\title{
Aplikasi Kamus Audio Bahasa Indonesia untuk Siswa BIPA (Bahasa Indonesia Penutur Asing)
}

\author{
Ilmatus Sa'diyah, S.Pd., M.Hum. \\ Prodi Sains Data Fakultas Ilmu Komputer UPN "Veteran” Surabaya Jawa Timur \\ *Corresponding author email:ilmatus.sisfolupnjatim.ac.id
}

\begin{abstract}
Abstrak - Teknologi hadir dan masuk dalam semua sektor kehidupan, termasuk bidang bahasa. Dalam hal ini, bahasa Indonesia juga menyesuaikan dengan kehadiran teknologi agar bahasa Indonesia semakin diminati oleh pengguna teknologi, terutama siswa BIPA. Kamus bahasa Indonesia pun sudah dibuat dalam bentuk kolaborasi dengan teknologi sehingga sudah dibuat dalam tampilan aplikasi dan laman. Sayangnya, kamus itu hanya bisa dibaca oleh siswa dari Indonesia. Sementara itu, untuk siswa BIPA (Bahasa Indonsia Penutur Asing), belum ada kamus bahasa Indonesia yang sesuai dengan tujuan belajar. Oleh karena itu, penelitian ini dilakukan untuk menciptakan kamus bahasa Indonesia untuk siswa BIPA. Penelitian ini menggunakan metode pengembangan Thiagarajan. Setelah dibuat, kamus ini menunjukkan penampilan yang layak digunakan oleh siswa BIPA sebagai teman belajar bahasa Indonesia.
\end{abstract}

Kata Kunci- kamus bahasa Indonesia, aplikasi kamus, siswa BIPA.

\section{Pendahuluan}

Sejumlah dokumen kebahasaan sebagai penunjang pembelajaran Bahasa Indonesia sudah disusun oleh Kementerian Pendidikan dan Kebudayaan melalui Badan Bahasa. Dokumen itu meliputi Kamus Besar Bahasa Indonesia secara daring, Kamus Bahasa Indonesia untuk pelajar (khusus SLTP dan SLTA), Glosarium via daring, Kamus Bidang Ilmu, Kamus Dwibahasa, dan Tesaurus Alfabetis. Seluruh dokumen sudah dibuat dalam bentuk daring dan disesuaikan dengan kemajuan teknologi. Sayangnya, masih ada satu dokumen yang belum sesuai dengan kebutuhan siswa BIPA. Dokumen itu adalah kamus Bahasa Indonesia. Kamus yang sudah disusun oleh Badan Bahasa bersifat umum sehingga dapat digunakan dalam semua aktivitas masyarakat dan keilmuan. Kamus itu belum disesuaikan dengan kebutuhan siswa BIPA.

Pada dasarnya, siswa BIPA membutuhkan Kamus yang sesuai dengan kondisi kemampuan bahasanya, yaitu kamus dwibahasa dan memiliki audio yang berisi cara mengucapkan kosakata itu dalam Bahasa Indonesia. Kosakata yang dimasukkan pun masih tingkat dasar bahasa Indonesia yang dilengkapi dengan contoh konteks kalimat dan bunyi kata tersebut secara lisan. Kamus tersebut dibuat dalam bentuk aplikasi yang dapat diinstal di smartphone. Menurut Budiwiyanto [1], penyusunan Kamus Bahasa Indonesia dengan model dwibahasa dan audio untuk Penutur Asing menjadi kebutuhan yang harus disegerakan karena sangat penting.

Secara bentuk, bahasa Indonesia mempunyai perbedaan antara bahasa lisan dan bahasa tulis. Misalnya pada kata /kuitansi/ yang diucapkan secara lisan menjadi /kwitansi/ dengan membunyikan huruf $<\mathrm{w}>$. Perbedaan tersebut menimbulkan kesulitan siswa BIPA tingkat pemula dalam mempelajari perbedaan pelafalan bunyi bahasa Indonesia, khususnya huruf diftong /ui/ yang ketika dilafalkan memunculkan huruf /w/. Bisa jadi, siswa BIPA akan membunyikan kata/kuitansi/ menjadi /kuitansi/ tanpa huruf /w/.

Kondisi itu tentu memberikan dampak yang serius pada kesuksesan pembelajaran menyimak dan berbicara. Siswa BIPA kesulitan untuk belajar mandiri di rumah. Siswa BIPA akan cenderung mengandalkan materi belajar yang diberikan oleh pengajar di kelas. Ujungnya, siswa BIPA akan memiliki perkembangan belajar yang lambat.

Sejauh ini, Badan Bahasa memang hanya memiliki dokumen yang mendukung ketepatan penggunaan Bahasa Indonesia di masyarakat umum secara tertulis. Aspek lisan dari Bahasa Indonesia belum ada atau dikenal dengan istilah Pedoman Pelafalan Bahasa Indonesia [2]. Jadi, Kamus Audio Bahasa Indonesia memang perlu diciptakan. Hanya saja, pada pembuatan tahap pertama, kamus ini diperuntukkan bagi siswa BIPA sebagai penunjang pembelajaran, terutama pada keterampilan menyimak dan berbicara yang berkaitan dengan aspek lisan kebahasaan.

Secara umum penelitian ini bertujuan menciptakan kamus Bahasa Indonesia bernama KABI dengan aspek audio dengan bentuk aplikasi. Secara khusus, tujuan penelitian ini adalah (1) mendeskripsikan proses pembuatan, (2) mendeskripsikan bentuk kamus, (3) dan mendeskripsikan penggunaan kamus di kelas BIPA.

\section{TEORI}

Kamus menjadi sumber informasi utama dalam pembelajaran bahasa kedua dan Bahasa asing, terutama bagi siswa yang baru belajar [3]. East [4] menyatakan bahwa siswa memerlukan informasi berupa arti kata, bentuk kata, penggunaan kata dalam bahasa lain dari kamus, dan makna kata. Meskipun pembelajaran bahasa kedua dan bahasa asing lebih banyak menekankan pada pendekatan komunikatif, siswa masih membutuhkan akses untuk mencari kata dan maknanya bahkan mempelajari cara melafalkannya dari kamus [5].

Pada mulanya, kamus sudah ada dan dikembangkan berbentuk buku yang disebut sebagai kamus konvensional. Arief, dkk [6] menyatakan bahwa kamus konvensional yang berbentuk buku bersifat monoton atau stagnan, tidak bisa menambah kosakata baru ataupun diubah, serta tidak efektif dalam segi pencarian kata karena membutuhkan waktu yang cukup lama untuk mencari kosakata. Oleh karena itu, teknologi membantu mengatasi kekurangan dari kamus 
konvensional dengan adanya kamus elektronik yang mempunyai kelebihan, yaitu lebih efisien dalam pencarian arti kata sehingga tidak membutuhkan waktu lama dan dapat diperbarui sehingga tidak membosankan [7]. Oleh karena itu, kamus elektronik diterima dan digunakan dengan baik oleh seluruh siswa bahasa asing pada semua level sehingga kamus elektronik sudah menjadi alternatif mencari informasi makna kata [8].

Kemudian, teknologi berkembang lagi dengan adanya teknologi mobile yang memberikan keuntungan berupa kemudahan dalam belajar (di mana pun dan kapan pun) yang perkembangannya dikenal dengan istilah MALL (MobileAssisted Language Learning) sehingga siswa tidak harus di kelas [9]. Perkembangan itu berdampak terhadap pengembangan kamus elektronik berbentuk aplikasi dalam smartphone.

Mobile apps dalam smartphone terdiri atas aplikasi yang bervariasi yang dapat membantu siswa untuk memanajemen waktu belajar lebih efektif, satu di antaranya adalah mobile dictionaries [10]. Mobile dictionaries memiliki beberapa keunggulan, yaitu memiliki jumlah kata, frasa, kolokasi, idiom, sinonim, dan antonim lebih banyak, memberikan contoh pelafalan kata, dan dapat menunjukkan gambar dan video yang berhubungan dengan makna kata. Penggunaan kamus mobile dapat meningkatkan kemampuan berbahasa siswa bahasa kedua secara lebih efektif dibandingkan dengan menggunakan kamus cetak [10]. Bahkan, untuk meningkatkan keefektifannya, Blake [11] mengharap adanya kamus yang dapat memudahkan siswa mencari arti kata saat menonton video di youtube dengan sekali klik.

Selain berupa aplikasi, kamus juga perlu dilengkapi dengan teknologi audio berupa text-to-speech facility yang memungkinkan untuk mendengar lafal setelah memasukkan entri kata dalam kamus [12]. Keberadaan audio dalam kamus itu dapat membantu siswa dalam menyimak, meniru cara melafalkan kata, meningkatkan daya mendengar, dan meningkatkan suasana aktif di kelas [13]. Audio itu menjadi keunggulan KABI karena dapat melatih pelafalan baku bahasa Indonesia siswa BIPA.

Kamus berbasis aplikasi dan audio ini berupa kamus monolingual. Tipe kamus ini dipilih karena beberapa keunggulan yang dimilikinya, yaitu siswa akan berpikir dalam bahasa target, mempercepat volume pemerolehan kata, meningkatkan rasa ingin tahu siswa, dan panduan guru selalu dibutuhkan pada tingkat dasar dan menengah [14].

KABI juga mempertimbangkan aspek tingkat siswa sehingga membutuhkan korpus siswa berdasarkan tingkatannya yang dikumpulkan dari buku teks siswa BIPA tingkat A [15]. Kamus berbasis aplikasi ini akan dibuat dengan sistem android. [16] menyatakan bahwa android merupakan subset perangkat lunak untuk perangkat mobile yang meliputi sistem operasi, middleware, dan aplikasi inti yang dirilis oleh google. Oleh karena itu, KABI menjadi kamus yang berintegrasi dengan teknologi untuk mencapai pembelajaran bahasa Indonesia yang efektif.

\section{METODE PENELITIAN}

Jenis penelitian ini merupakan penelitian dan pengembangan (research and development). Metode ini dipilih karena tujuan umum penelitian ini adalah untuk menghasilkan sebuah produk, yaitu kamus audio bahasa Indonesia. Metode ini menggunakan model pengembangan Thiagarajan, 4-D yang meliputi define, design, develop, dan disseminate yang diadaptasi menjadi 4-P, yaitu pendefinisian, perancangan, pengembangan, dan penyebaran. Namun, penelitian ini hanya dilakukan sampai pada tahap pengembangan karena penelitian ditujukan untuk penelitian tahap ke-1. Tahap penyebaran akan dilakukan sebagai penelitian tahap ke-2. Pada tahap itu, kamus dapat diujicoba keefektifannya pada konteks belajar dan subjek belajar, yaitu siswa IPA.

Pada tahap perencanaan, terdapat lima langkah pokok, yaitu analisis ujung depan, analisis tugas, analisis konsep, dan analisis tujuan pembelajaran yang dilakukan berurutan, tetapi dalam satu framework [17]. Analisis ujung depan adalah pemberlakuan sistem kurikulum. Sejalan dengan hal itu, kurikulum yang digunakan saat ini mengacu pada kurikulum BIPA secara umum. Setelah mengidentifikasi kurikulum, analisis kebutuhan siswa BIPA dilakukan untuk mengetahui kebutuhan siswa BIPA dalam mempelajari bahasa Indonesia melalui kamus. Kebutuhan siswa yang telah didapatkan digunakan untuk menganalisis tugas sehingga dapat menentukan materi pembelajaran [17]. Analisis tugas dilakukan untuk memerinci isi dalam buku teks BIPA tingkat A1 dan A2 yang diterbitkan oleh pusat bahasa. Selanjutnya, analisis konsep bertujuan mengidentifikasi fakta, konsep, prinsip, dan aturan yang dibutuhkan dalam pengajaran BIPA. Cara yang digunakan untuk mengidentifikasi konsep adalah dengan membuat peta konsep pengajaran keterampilan menyimak. Hasil dari analisis ujung depan, kebutuhan siswa BIPA, konsep, dan tugas digunakan untuk merumuskan tujuan pembelajaran. Tujuan ini selanjutnya menjadi dasar bagi penyusunan kamus.

Tujuan pembelajaran yang telah dirumuskan diimplementasikan dalam merancang format kamus pembelajaran (KABI). Format yang telah dibuat dijadikan dasar dalam pembuatan desain awal. Kedua tahap ini berada dalam tahap perancangan. Selanjutnya, kamus berupa desain awal diujicobakan secara terbatas kepada lima siswa BIPA dan divalidasi kepada dosen ahli. Dari uji coba dan validasi, KABI direvisi kembali sehingga didapatkan kamus yang berkualitas dan efektif.

Teknik pengumpulan data yang digunakan pada penelitian ini dibedakan berdasarkan masalah yang akan diteliti. Terdapat dua teknik pengumpulan data, yaitu angket dan tes. Angket yang digunakan bersifat tertutup dan terbuka yang dibedakan menjadi dua, yaitu angket kualitas kamus (angket untuk dosen dan angket untuk pengajar BIPA) dan angket respons siswa BIPA.

Proses pengembangan dianalisis dengan metode deskriptif kualitatif. Dokumen-dokumen yang ada digunakan untuk menguatkan deskripsi tentang proses pengembangan tersebut. Data hasil validasi dari dosen, pengajar BIPA, dan angket siswa direkapitulasi, dianalisis secara deskriptif kuantitatif, kemudian dianalisis dengan menggunakan rumus. 


\section{$\mathrm{P}=$ jumlah skor seluruh validator $\mathrm{x} 100 \%$ Jumlah skor maksimal $\mathrm{P}=$ Penilaian}

\begin{tabular}{|l|l|c|c|}
\hline & menyimak? & & \\
\hline 7 & $\begin{array}{l}\text { Apakah jenis kamus yang Anda } \\
\text { gunakan adalah bilingual. }\end{array}$ & $100 \%$ & 0 \\
\hline 8 & $\begin{array}{l}\text { Apakah kamus elektronik yang } \\
\text { Anda gunakan memiliki fungsi } \\
\text { audio? }\end{array}$ & $27 \%$ & $73 \%$ \\
\hline
\end{tabular}

\section{IV.PEMBAHASAN}

Berdasarkan hasil penelitian yang telah dilakukan, diuraikan tiga hal, yaitu proses, bentuk, dan penggunaan kamus. Berikut ini merupakan uraian tiap-tiap subbabnya.

\subsection{Proses Pengembangan Kamus KABI}

Kurikulum yang digunakan dalam penelitian adalah kurikulum BIPA di LBI. Keterampilan menyimak dipilih sebagai materi pembelajaran. Materi keterampilan menyimak di buku BIPA tingkat A1 dan A2 tersebar dalam setiap unit pembelajaran bersama dengan tiga keterampilan lainnya. Dalam buku A1, terdapat sepuluh unit materi pembelajaran dalam sepuluh tema, yaitu menyapa, berkenalan, keluargaku, selamat ulang tahun, jalan-jalan, penyayang binatang, petunjuk arah, kegiatan sehari-hari, rumah Santi, dan lagu populer Indonesia. Sementara itu, dalam buku A2, terdapat dua belas unit materi pembelajaran dalam dua belas tema pembelajaran, yaitu keluarga besar saya, kegiatan sehari-hari, mari berbelanja, rumah Asti, makanan Indonesia, kegemaran, film, pekerjaan, tetangga baru, berolahraga, transportasi, dan jalan-jalan. Keseluruhan tema digunakan dalam membuat konsep KABI dan menyusun daftar kosakata yang dimasukkan dalam KABI. Daftar kosakata itu menjadi korpus dalam penyusunan kamus. Penyesuaian terhadap dua buku BIPA tingkat A dilakukan untuk membantu siswa tingkat pemula memahami isi buku dan mencapai target pembelajaran dalam kurikulum.

Sebelum KABI dikembangkan, dilakukan kegiatan analisis kebutuhan dan perspektif siswa BIPA di LBI UI terhadap penggunaan kamus dalam pembelajaran. Analisis itu dilakukan melalui angket terbuka (lihat tabel 3).

Tabel I. Representasi Analisis Kebutuhan dan Perspektif Siswa BIPA

\begin{tabular}{|c|c|c|c|}
\hline No & Pertanyaan & Ya & Tidak \\
\hline 1 & $\begin{array}{l}\text { Apakah pernah belajar bahasa } \\
\text { Indonesia sebelumnya? }\end{array}$ & $20 \%$ & $80 \%$ \\
\hline 2 & $\begin{array}{l}\text { Dari empat keterampilan, apakah } \\
\text { keterampilan menyimak } \\
\text { termasuk paling susah dipelajari? }\end{array}$ & $93 \%$ & $7 \%$ \\
\hline 3 & $\begin{array}{l}\text { Apakah jenis huruf bahasa } \\
\text { Indonesia susah dieja dan } \\
\text { didengarkan? }\end{array}$ & $67 \%$ & $33 \%$ \\
\hline 4 & $\begin{array}{l}\text { Apakah Anda pernah belajar } \\
\text { bahasa Indonesia dari aplikasi } \\
\text { yang ada di smartphone? }\end{array}$ & $100 \%$ & 0 \\
\hline 5 & $\begin{array}{l}\text { Apakah Anda masih } \\
\text { membutuhkan kamus saat belajar } \\
\text { bahasa Indonesia di kelas? }\end{array}$ & $100 \%$ & 0 \\
\hline 6 & $\begin{array}{l}\text { Apakah Anda sering } \\
\text { menggunakan kamus saat }\end{array}$ & $47 \%$ & $53 \%$ \\
\hline
\end{tabular}

Pada tabel I, pertanyaan yang tidak sesuai ekspektasi peneliti adalah jenis kamus yang digunakan siswa BIPA. Peneliti mengira bahwa siswa akan menggunakan kamus jenis monolingual. Saat dikonfirmasi melalui angket, siswa menggunakan kamus bilingual Inggris-Indonesia atau bahasa Indonesia dengan bahasa asli tiap-tiap siswa. Hal itu sesuai dengan kondisi siswa pemula bahasa asing yang belum memiliki jumlah kosakata bahasa Indonesia dalam jumlah banyak. Oleh karena itu, poin ini menjadi pertimbangan dalam penyusunan kamus KABI. Selain itu, bagi siswa pemula, keterampilan menyimak menjadi keterampilan yang susah dipelajari karena memiliki huruf yang berbeda, seperti /r/, /ng/, dan /ny/. Hal itu berdampak pada keseluruhan siswa yang masih membutuhkan kamus saat belajar (100\%).

Tahap perancangan merupakan tahap yang meliputi penentuan unsur-unsur yang perlu dimasukkan dalam pembuatan kamus KABI bagi pembelajar BIPA. Unsur-unsur yang dimasukkan tersebut adalah huruf dalam bahasa Indonesia, kosakata sehari-hari berfrekuensi tinggi dalam buku BIPA, dan kata turunan. Setelah dirancang, pembuatan aplikasi pada smartphone diserahkan pada ahli IT, Kahfi Zein.

Selanjutnya, kamus KABI divalidasi oleh ahli dan pengajar BIPA dari tiga aspek, yaitu aspek isi, penyajian, dan kegrafikaan. Selain divalidasi, kamus KABI diimplementasikan di kelas (15 siswa). Dari hasil validasi, penilaian, dan implementasi, perbaikan pada media KABI perlu dilakukan.

Penilaian kualitas media KABI diberikan oleh ahli dan pengajar BIPA. Nilai terendah adalah dua dengan kualifikasi kurang baik dan skor tertinggi adalah empat dengan kualifikasi sangat baik. Skor terendah pada aspek pemilihan gambar pada media. Skor terendah kedua pada aspek pengelompokan kata. Pengelompokan kata belum dilakukan dalam draf awal media KABI. Kemudian, pada draf akhir telah dikelompokkan menjadi kata kerja, kata benda, kata sifat, kata bilangan, dan kata majemuk. Skor pada aspek penilaian didominasi oleh nilai 3 dan 4. Secara umum, penilaian terbaik oleh semua validator pada aspek kemudahan untuk diakses karena KABI akan di-share pada google play secara gratis. Berikutnya, pada aspek makna kata yang dapat dimaknai dengan mudah. Kemudian, keunggulan berikutnya dari KABI adalah kemudahan untuk diinstal dan dioperasikan, jumlah kosakata, dan dapat meningkatkan kemampuan menyimak.

Media KABI diuji tingkat keefektifan pada saat implementasi. Pengujian tingkat keefektifan pada BIPA dilakukan pada siswa BIPA. Keefektifan media KABI bagi BIPA diukur berdasarkan respons siswa BIPA setelah menjadi peserta implementasi dan rata-rata hasil tes. Respons yang diminta berupa respons bebas yang berbentuk uraian. Hal ini bertujuan mendapatkan saran sebagai bahan perbaikan. Pada pembelajaran keterampilan menyimak, skor rata-rata siswa BIPA adalah 82,07. Nilai itu menunjukkan bahwa media 
KABI terkategori baik digunakan dalam meningkatkan pembelajaran menyimak. Selain itu, siswa BIPA juga memberikan komentar dan saran untuk perbaikan KABI ke depan. Perbaikan itu mencakup bentuk dan isi kamus KABI.

\subsection{Bentuk Kamus KABI}

Pada awal pembuatan, kamus KABI masih terdiri atas 300 kosakata. Kosakata ini akan terus ditambah jumlahnya agar semakin bisa memfasilitasi siswa BIPA dalam belajar. Seluruh kosakata itu dikelompokkan berdasarkan jenis kosakata. Pengelompokan dilakukan untuk mempermudah siswa mengenali jenis kata sehingga KABI dapat digunakan dalam pembelajaran kosakata.

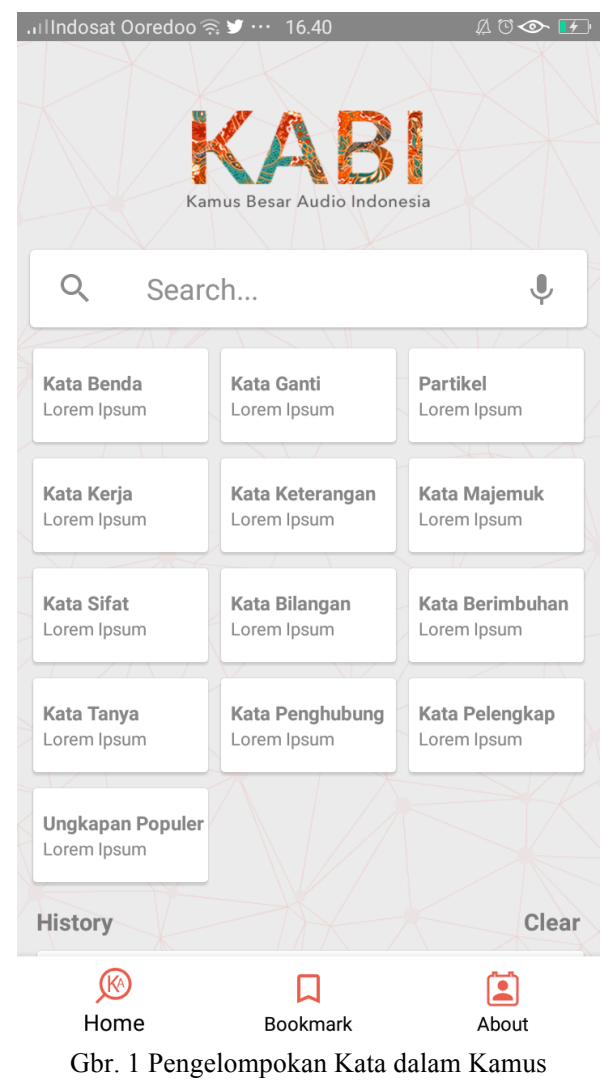

Pada gambar 1, pengelompokan kata dalam kamus meliputi kata benda, kata ganti, partikel, kata kerja, kata keterangan, kata majemuk, kata sifat, kata bilangan, kata berimbuhan, kata tanya, kata penghubung, kata pelengkap, dan ungkapan popular. Bagian ungkapan populer seharusnya bukan termasuk dalam jenis kata. Namun, hal itu penting ditunjukkan kepada siswa BIPA karena dalam konteks komunikasi langsung dengan penutur asli Bahasa Indonesia, siswa BIPA tidak selamanya menggunakan ragam bahasa formal, tetapi perlu menggunakan ragam bahasa nonformal yang berbentuk ungkapan populer.

Selain pengelompokan kata, kamus KABI juga dilengkapi dengan audio yang muncul saat kosakata diinput oleh siswa ke dalam kamus. Sayangnya, audio yang muncul dalam kamus bukanlah suara asli penutur bahasa Indonesia. Hal itu disebabkan oleh belum ada ketetapan suara penutur daerah mana dari Indonesia yang bias dijadikan acuan. Apakah dari daerah Jawa, Batak, atau Sunda. Penentuan itu belum begitu jelas. Pertimbangan lain juga turut berpengaruh, yaitu pada memori aplikasi ketika di-instal dalam smartphone. Pasalnya, aplikasi sudah menjadi berat setelah memasukkan aspek gambar ke dalam kamus.

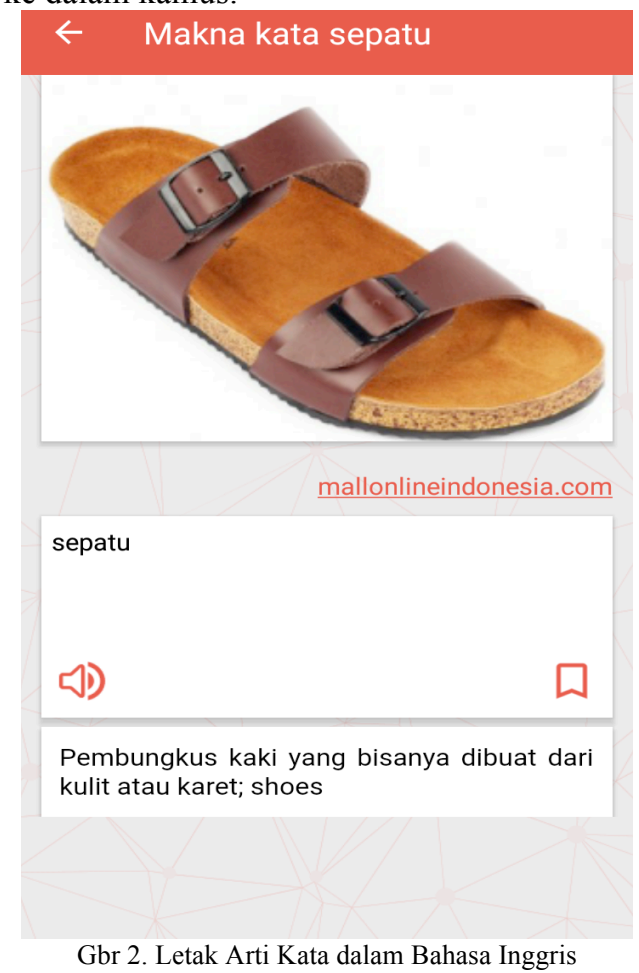

Pada aspek makna kata, dalam kamus KABI juga ditambahkan arti kata dalam bahasa Inggris pada ujung makna kata sehingga KABI bersifat bilingual secara tidak langsung (lihat gambar 2). Kata orang tua dan sepatu diberikan padanan dalam bahasa Inggris parents dan shoes. Padanan dalam bahasa Inggris ini disesuaikan dengan hasil analisis kebutuhan siswa BIPA terhadap kamus dwibahasa, IndonesiaInggris.

Pada aspek penyajian, media KABI draf awal tidak menyertakan gambar apa pun sebagai pemotivasi atau peransang semangat belajar. Hal itu mendapat saran perbaikan dari siswa untuk menambahkan unsur gambar dan video. Oleh karena itu, ditambahkan gambar pada media KABI sehingga KABI tidak lagi berbasis aplikasi dan audio, melainkan juga visual. Gambar yang dimasukkan juga diupayakan bermuatan budaya Indonesia (lihat gambar 2). Budaya Indonesia ini dimaksudkan untuk mengenalkan budaya asli Indonesia. Gambar sepatu sengaja dipilih terbuat dari kayu yang juga khas Indonesia.

Karena gambar diambil dari sumber kedua, yaitu google, muncul masalah baru. Gambar yang sudah dimasukkan ke dalam kamus akhirnya menghilang seiring dengan hilangnya gambar dari sumber utama. Hal ini harus terus dicek oleh IT kamus agar tidak mengecewakan saat diakses oleh siswa BIPA. Ketika gambar menghilang, gambar harus lekas diganti dengan gambar dari sumber lain. 


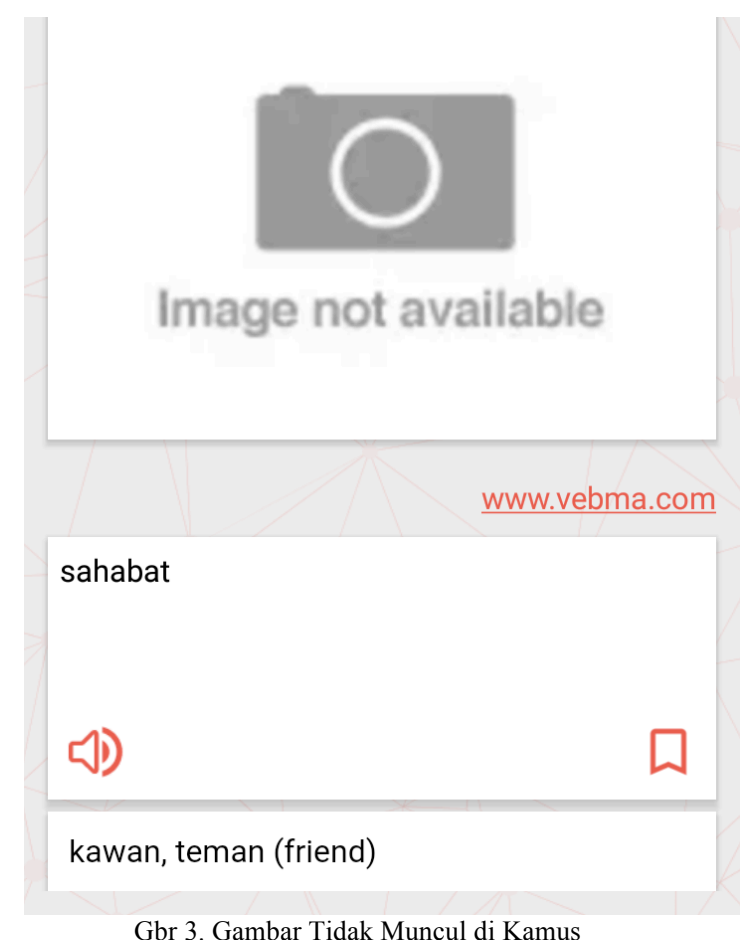

Desain disesuaikan dengan budaya Indonesia sehingga terdapat usaha menumbuhkan rasa cinta pada diri siswa BIPA. Desain yang ditambahkan berupa gambar ikon-ikon Indonesia, seperti Candi Borobudur, dan Tugu Monas. Tampilan awal saat membuka aplikasi KABI muncul gambar batik dan peta Indonesia (lihat gambar 4).

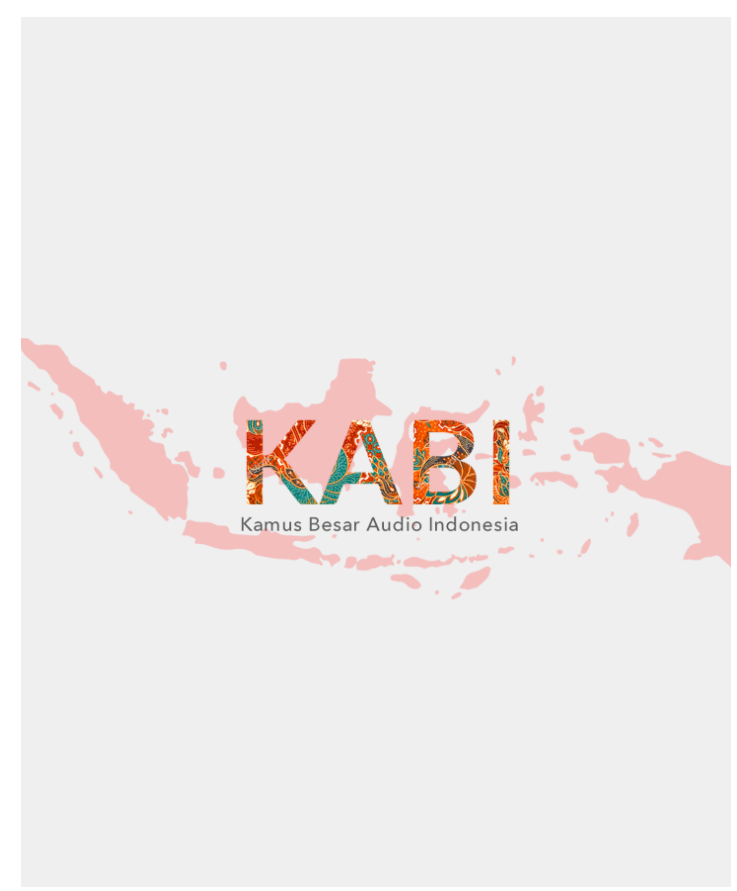

Gbr. 4. Tampilan Awal KABI

\subsection{Penggunaan Kamus KABI}

Sesuai dengan alasan mendasar pembuatan kamus KABI, kamus ini dapat digunakan sebagai media pembelajaran di kelas BIPA. Sebagai media pembelajaran, tentu kamus ini akan diunggah ke playstore agar bisa diakses. Untuk sementara, pengajar juga bisa membagikan aplikasi kamus KABI melalui aplikasi share it.

Sebagai media pembelajaran, kamus KABI bisa digunakan pada aspek keterampilan berbahasa, baik keterampilan menyimak, berbicara, membaca, dan menulis. Pada tahap uji coba, kamus ini diterapkan pada keterampilan menyimak dan menunjukkan keefektifan. Oleh karena itu, penggunaan kamus KABI pada aspek keterampilan berbahasa lainnya menjadi gap untuk penelitian selanjutnya.

\section{SIMPULAN}

Dari penelitian yang sudah dilakukan, penelitian ini sudah efektif. Aplikasi kamus KABI yang dibuat sesuai dengan kebutuhan siswa BIPA. Hanya saja, kamus ini memang masih perlu ditambah dari segi korpus. Oleh karena itu, peneliti selanjutnya bisa melanjutkannya.

\section{REFERENSI}

[1] Riasa, N. Abstrak Sidang Paralel KIPBIPA 2015. Diakses pada $18 \quad$ Februari 2017, dari http://kipbipa9.apbipaindonesia.org, 2015

[2] Muslich, M. Fonologi Bahasa Indonesia: Tinjauan Deskriptif Sistem Bunyi Bahasa Indonesia. Jakarta: Bumi Aksara. 2009

[3] Huang, S. \& Eslami, Z. The Use of Dictionary and Contextual Guessing Strategies for Vocabulary Learning by Advanced English-Language Learners. English Language and Literature Studies, 3 (3), 1-7. 2013

[4] East. M. Dictionary Use in Foreign Language Writing Exams. Amsterdam/Philadelpia: John Benjamins Publishing Company.2008

[5] Marmol, G. A., \& Sanchez-Lafuente, A.A.The Bilingual Dictionary and Foreign Language Learning: Facts and Opinions. Porta Linguarum, 20, 89-101. 2013

[6] Arief, N. Aplikasi Kamus Online Bahasa Arab Indonesia. (Skripsi Sarjana, Universitas Diponegoro, 2016). Diakses dari http://undip.lib.ac.id. 2016

[7] Golonka, E.M., Bowles, A.R., Frank, V.M., Richardson, D.L., \& Freynik, S. Technologies for Foreign Language Learning: A Review of Technology Types and Their Effectiveness. Computer Assisted Language Learning Rouledge Taylor \& Francis Group., 27 (1), 70-105. 2014

[8] Abdollapour, Z. \& Maleki, N.A. (2012). Second Language Vocabulary Acquistion in CALL and MALL Environments and Their Effect on L2 Vocabulary Retention: A Comparative Study. Australian Journal of Basic and Applied Sciences, 6(9), 109-118

[9] Palalas, A. Mobile-Assisted Language Learning: Designing for Your students. Dalam Thouesny, S. \& Bradley, L (Ed): Second Language Teaching and Learning 
with Technology: Views of Emergent Researchers (h. 7193)., research-publishing.net 2011

[10] Rahimi, M. \& Miri, S.S. The Impact of Mobile Dictionary Use on Language Learning. Procedia-Social and Behavioral Sciences, 98, 1469-1474. 2014

[11] Blake, R. Technology and the Four Skills. Language Learning \& Technology, 20 (2), 129-142. 2016

[12] Deksne, D., Skadina, I. \& Vasiljevs, A. (2013). The Modern Electronic Dictionary that Always Provides an Answer. Proceedings of eLex. $421-434$

[13] Sedighi, S. \& Soyoof, A. Smartphone Application: A Superior Tool to Learn a New Language. International Conference "ICT for Language Learning" 6th Edition. 2012

[14] Underhill, A. Working with the Monolingual Learners' Dictionary. Dalam Fit, C.J.B.R (Ed): Dictionaries, Lexicography and Language Learning: English Language Teaching Documents (h. 103-114). Oxford: Pergamon Press. 1985

[15] Lew, R. Dictionaries and Technology. The Encyclopedia of Applied Linguistics. Dalam In Chapelle, C. (Ed): Dictionaries and Technology. Oxford: Wiley-Blackwell. 2013

[16] Parno, dkk. Aplikasi Mobile Kamus Istilah Psikologi Berbasis Android 2.2. Psikologi, Ekonomi, Sastra, Arsitektur, dan Sipil, 4, 121-128 . 2011

[17] Trianto. Model Pembelajaran Terpadu dalam Teori dan Praktek. Jakarta: Prestasi Pustaka. 2007.

[18] Arikunto, S. Prosedur Penelitian : Suatu Pendekatan Praktik. Jakarta : Rineka Cipta. 2010 